\title{
Survey of Use of Magnesium \\ Sulphate in Anaesthesia in Brazil
}

Ferreira N., Verçosa N., Lima F., Cavalcanti I.

\section{BACKGROUND AND GOALS}

In recent years has increased the interest in use of magnesium sulphate as an adjuvant drug in anaesthesia for its effects on autonomic response, cardiac arrhythmia, bronchospasm, neuroprotection. The aim of this study was determine how brazilian anaesthetists use magnesium sulphate in anaesthesia.

\section{METHODS}

\section{RESULTS}

Prospective transversal survey. After ethical approval, questionnaire was sent to 9869 anaesthetists members of the Brazilian Society of Anesthesiology (BSA). Anaesthetists were invited to participate for 3 consecutive occasions with an interval of 15 days between them, through e-mail sent directly by the BSA. Data were submitted to descriptive statistics.

\section{CONCLUSION}

Thirty five per cent of brazilian anaesthetists that answered the survey used magnesium sulphate during anaesthesia on different clinical indications. The results demonstrated potential importance of adjuvant drugs as anaesthesia component, particularly magnesium sulphate.

Reference: Herroeder S, Schönherr ME, De Hert SG, Hollmann MW. Magnesium - essentials for
Commonly EV dose on general anaesthesia: Induction: $30-40 \mathrm{mg} \cdot \mathrm{kg}^{-1}$

Maintenance $<30 \mathrm{mg} \cdot \mathrm{kg}^{-1}$.

$$
\text { MAIN INDICATIONS }
$$

$\%$

Postoperative analgesia

72,70

Reducing the consumption of anesthetics

71,21

Eclampsia

65,28

Cardiac arrhythmias

52,52

Less consumption of neuromuscular blockers

50,44

Prevention of chronic pain after surgery

50,14

Bronchodilation

49,55

Prevention hyperalgesia after remifentanila

48,07

Hypomagnesemia prevention

38,57

Induced hypotension

34,12

Pheochromocytoma

21,95

Prevention / treatment of emerging agitation

19,58

Inhibition of premature labor

17,80

Intubation without neuromuscular blockers

13,94

Reduction of surgical bleeding

Prevention / treatment of laryngospasm

11,86

\begin{tabular}{|l|l|}
\multicolumn{1}{|c|}{ COMPLICATIONS } & $\%$ \\
\hline Arterial hypotension & 55,48 \\
\hline Residual neuromuscular blockade & 39,46 \\
\hline No complications & 11,86
\end{tabular}

